\title{
SIEMPRE SE ESCRIBE CONTRA ALGO ... \\ BARBARIE, DICTADURA Y MEMORIA DESDE LA PATAGONIA. ENTREVISTA CON LUISA PELUFFO
}

\author{
POR \\ Claudia Hammerschmidt \\ Friedrich-Schiller-Universität Jena
}

La narradora y poeta Luisa Peluffo, autora de una vasta obra que abarca libros tan heterogéneos como Materia viva (poemas, 1976), Conspiraciones (cuentos, 1982), Materia de revelaciones (poemas, 1983), Todo eso oyes (novela, 1989), La otra orilla (poemas, 1991), La doble vida (novela, 1993), Un color inexistente (poemas, 2001), Si canta un gallo (teatro, 2006), Me voy a vivir al sur (crónica, 2005), Nadie baila el tango (novela, 2009), Se llaman valijas (cuentos, 2012) y foto grafias (poemas, 2014), desde hace cuarenta años vive en Patagonia. En febrero de 2017, medio año antes de que estallaran los graves conflictos acerca de la desaparición de Santiago Maldonado el 1 de agosto de 2017 en la zona de Esquel, la autora habló de sus experiencias de vida en el Sur durante y después de la dictadura. La charla tuvo lugar en un pequeño café de Buenos Aires, donde Peluffo desarrolló todo un panorama de la nueva literatura patagónica y de su propia narrativa.

Claudia Hammerschmidt: Para comenzar quiero preguntarte cuándo te fuiste a vivir a Bariloche y cuáles fueron las razones.

Luisa Peluffo: Bueno, primero te aclaro que soy una ‘exporteña' y que nos radicamos en el sur con mi marido en 1977 con un hijo de tres años (nuestro segundo hijo nació en Bariloche). Nos radicamos en el sur porque llegó un momento en que no aguantamos más el clima de violencia que se vivía en Buenos Aires. Para estas cosas siempre hay como un detonante, como la gota que rebalsa el vaso, y eso fue una tarde en que había un embotellamiento en el centro y mi marido ve que del auto que iba delante del taxi en que él viajaba, baja un hombre armado con una ametralladora y los amenaza para que le den paso, porque si no "van a ser boleta" (significa que los van a matar). Otro detonante fue estar en la calle con mi hijo en su cochecito y enterarme de que a una cuadra acababa de estallar una bomba. Era una época de grandes cambios políticos en la Argentina, con el surgimiento de la guerrilla y el peronismo revolucionario. Esto fue antes del setenta y siete, incluso fue antes del setenta y seis. Ya había un clima de 
violencia muy grande, sobre todo en Buenos Aires. Perón regresa del exilio en 1972, asume la presidencia en 1973 y muere en 1974, dejando como presidenta a María Estela Martínez de Perón, su viuda, cuyo asesor y hombre de confianza era José López Rega - un asesino que comandaba bandas paramilitares- a quien ella nombra ministro de Bienestar Social; Ministerio del que dependía el PAMI (la obra social de los jubilados) donde trabajaba mi marido. Ahí fue que empezamos a pensar que nos teníamos que ir de Argentina. Primero pensábamos ir a España, pero en España estaba Franco, una dictadura. Y entonces, hablando con amigos y conocidos que habían venido al sur algunos años antes... y bueno, decidimos venir a Bariloche. Yo creo que pensamos en Bariloche por la sensación de que al sur del Río Colorado empezaba otro país, y era como irnos, pero no del todo, y también porque los dos conocíamos el lugar por haber venido en vacaciones. Poco tiempo después del golpe de Videla, en el setenta y seis, mi marido renunció a su trabajo en el PAMI por temor a integrar una lista de 'prescindibles'. Eran listas donde te fichaban como de izquierda, y en aquel momento eso equivalía a una denuncia seguida de secuestro y desaparición. Bueno, renunció, y a partir de ahí fue que tomó forma nuestra venida al sur. Y por suerte renunció, porque al año, secuestraron a su jefa de equipo en aquel trabajo, que es muy amiga nuestra. Ella no estaba metida en nada de política. No militaba. Probablemente la denunciaron en venganza por ser una mujer que, habiendo tenido un cargo directivo alto, nunca admitió ningún negocio sucio durante su gestión. El asunto es que la secuestran y gracias a dios la liberan al poco tiempo. Estuvo en un centro de detención que ya no existe más, lo tiraron abajo. Se llamaba "El Atlético" y quedaba en la avenida Paseo Colón. Dos hombres la someten a mucho interrogatorio, uno hacía de 'bueno', y su rol era convencerla de que hable, otro era el malo y la amenazaba. Y no sé si la torturaron, ella nunca quiso hablar mucho de eso, sé que la tuvieron "tabicada" (con los ojos vendados durante todo el tiempo que estuvo secuestrada) y que día y noche escuchaba el ruido de un juego de ping pong. Y un buen día la largaron, se movió mucha gente importante y tuvo suerte. Cuando a ella la agarran, nosotros ya no estábamos en Buenos Aires, estábamos en el sur, pero toda la gente de su equipo: arquitectos, psicólogos, sociólogos, que eran considerados de izquierda por los militares, tuvieron miedo y se tuvieron que mudar de casa. Nosotros nos enteramos de su secuestro bastante después, porque en esa época, en Bariloche, no había satélite, no había teléfono satelital, era el año 1977. Hoy día la gente joven no entiende eso, no había e-mail, no había nada. Para hablar por teléfono, una operadora te daba línea y podía escuchar tu conversación. Por este motivo, cuando una de mis hermanas se enteró de este secuestro, no quiso avisarnos por teléfono, ni escribirnos. Decidió tomar un avión para avisarnos. No sé adónde nos íbamos a esconder, porque en Chile estaba Pinochet. En medio de todo esto a nuestra amiga la liberan. Pero nosotros recién nos enteramos después, en un viaje que hicimos a Buenos Aires. Fue tremendo, le podría haber pasado a mi marido, o a cualquier

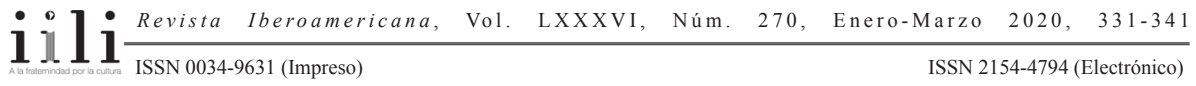


otro de ese equipo. Encima yo ya escribía y por ese solo hecho podían acusarme de 'subversiva', porque así clasificaban a las personas... Además, ya vivíamos una cosa muy paranoica, de sentirnos perseguidos, porque nadie daba nada por la vida de nadie. Vos estabas en la calle y te podían agarrar y meterte en el baúl de un auto y si alguien veía eso y decía algo lo llevaban también. Era terrible.

CH: La Patagonia en este momento entonces les parecía como alejada de todo, un lugar a dónde se podía escapar...

LP: Parecía alejada, pero por supuesto que no estaba alejada, porque fijate que en Bariloche al tiempo que nosotros llegamos secuestraron a Juan Herman, o sea que la represión se extendió por todos lados.

$\mathrm{CH}$ : ¿Pero eso se supo en ese momento ya?

LP: Se supo que lo habían llevado, pero nadie pensaba que la gente que llevaban no iba a volver. Pensabas: bueno, los tendrán presos en algún lugar. Nadie imaginaba el horror. Cómo iban a estar matando gente así... no te imaginabas, no te entraba en la cabeza. Podés imaginar que están detenidos sin juicio, lo que ya es un horror, pero bueno, en un momento dado les harán un juicio a la gente que actuó en acciones terroristas, pensábamos, pero los van a liberar, les van a hacer un juicio para ver si tienen algún motivo para tenerlos detenidos o no... Con el tiempo uno se empezó a preguntar: qué han hecho con esta gente, y empezaron las marchas de silencio... Las mismas madres y padres de los desaparecidos también tenían esperanza, porque a un hijo que te lo sacan vos no querés pensar que te lo mataron, querés pensar que está vivo.

$\mathrm{CH}$ : ¿Cuándo fue lo de Herman, en el mismo setenta y siete?

LP: Fue en julio del setenta y siete, creo, poco después de nuestra llegada. Yo me acuerdo muy bien que un día viene mi marido y me dice: mirá lo que pasó, se han llevado a Juan Herman. La familia de Juan Herman es una familia muy conocida en Bariloche, el padre era médico.

$\mathrm{CH}$ : Así que tampoco la Patagonia en aquel entonces fue un lugar seguro a dónde se podía escapar...

LP: No, para nada; la dictadura estaba presente en todas partes. Yo me acuerdo que cuando conocí a Graciela Cros -excelente poeta y amiga- que llegó de Buenos Aires a Bariloche antes que yo, dijimos bueno y por qué no nos juntamos en algo como una peña... y nos empezamos a juntar en pleno 1977 en nuestras casas, en el barrio Melipal, venían amigos, gente que conocíamos, pero había estado de sitio y empezó a caer gente que no conocíamos, y ahí nos empezó a dar miedo, cómo sabíamos que no eran de algún servicio de inteligencia. No sabías... Creo que nos reunimos cuatro o cinco veces y después la cortamos. Tampoco había noticias como ahora. Los diarios no decían nada. Los diarios, si llegaban, llegaban al mediodía a Bariloche y no informaban nada de todo esto. El único diario que tuvo la valentía de informar fue el Buenos Aires Herald, pero amenazaron a Robert Cox, su director, y a toda su familia, y se tuvo que

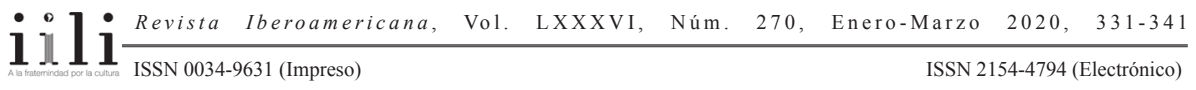


ir de la Argentina. Te enterabas a medias de lo que sucedía por el boca a boca. De repente alguien comentaba se llevaron a tal, pero lo decía meses después. O fulano se exilió. No siempre se sabía enseguida. De algunos casos yo me enteré después de mucho tiempo, como el de Lucía Cullen, a quien conocí de chiquita, y me impresionó mucho. Fue maquiavélico lo que hicieron los militares.

CH: Así que este lugar que habían soñado, una Patagonia arcádica, sin peligro, sin muerte, no existió; la dictadura también había entrado en el sur... ¿Cómo fue después de que la dictadura se terminó? ¿En 1983 en seguida se destaparon cosas?

LP: Lo que yo viví en Bariloche fue que, con la derrota de Malvinas en 1982, se fue como aflojando la situación porque ya los militares no tenían tanto poder, tenían toda la opinión pública en contra, por más que la opinión pública los apoyó en lo de Malvinas, porque este es un país muy nacionalista y esto no hay que olvidarlo: fueron a la plaza a vivarlo a Galtieri por Malvinas, y en el setenta y ocho festejaron el mundial de futbol organizado por los militares en plena dictadura. Pero la cosa se fue aflojando en el ochenta y dos, cuando pierden la guerra, y ahí yo me acuerdo que empezaron las marchas de silencio. En una marcha te pueden marcar, pero los tipos ya veían que se les venía encima un gobierno democrático. Pero fueron siete años de terror.

CH: Dentro de toda la situación maquiavélica de la que hablaste - ¿cómo se vivió la presencia de los alemanes en Bariloche? Ya hace bastante tiempo se supo de la presencia de muchos alemanes nazi en Bariloche. ¿Durante la dictadura, hubo una vinculación entre los militares y estos nazis en la zona, como la hubo por ejemplo en el sur de Chile?

LP: No lo sé... Mis dos hijos fueron a la escuela alemana, y cuando ingresaron, todo parecía normal, no parecían nazis. El tema Priebke se destapa cuando Carlos Menem (el presidente que sucede a Raúl Alfonsín en los noventa) permite que se abran archivos secretos de la época de Perón relacionados con el nazismo. Ahí se descubre lo de Priebke, que en ese momento presidía la Asociación Germano-Argentina de Bariloche de la que depende la escuela alemana Primo Capraro. Tremendo... Y esto se descubre gracias a que ya estábamos en democracia. En la época de los militares, Priebke era un tipo que tenía una rotisería y nadie se ocupaba de él, no era un personaje público. La primera noticia sobre él está en el libro de Esteban Buch, El pintor de la Suiza argentina, que es un libro publicado en 1991. Pero el libro de Buch está centrado en Toon Maes, un pintor belga que fue colaboracionista del nazismo. Buch se hace amigo de Toon Maes, quien le da una versión particular de su pasado colaboracionista. Pero Esteban Buch también incluye en su libro entrevistas a otros personajes vinculados al nazismo, entre las que figura una a Priebke, quien le revela su pasado nazi y su participación en la masacre de las Fosas Ardeatinas.

CH: ¿Pero entonces no hubo en Bariloche o en la Patagonia una conexión con los militares? 
LP: Probablemente había simpatía con toda esa cosa nazi por parte de los militares. Yo lo que sé es que, en la escuela alemana, en la época de los militares, no les hablaban a los chicos de los campos de concentración en Alemania. En los noventa sí, porque empezaron a venir profesores deAlemania Oriental. Y según los libros que se publicaron sobre Priebke, él pudo viajar a Alemania varias veces sin ningún problema, hasta que lo detuvieron...

$\mathrm{CH}$ : Con su mismo nombre, sin cambiárselo, es increíble...

LP: Qué difíciles son todas estas cosas, qué difícil es poder hacer justicia de las cosas que sucedieron. Porque Estados Unidos también recibió a muchos nazis después de la guerra. Y Perón contrató al físico austríaco Ronald Richter, que se instaló acá, en la isla Huemul, con el proyecto de lograr la fusión nuclear controlada y la bomba atómica.

$\mathrm{CH}$ : ¿Pero dirías que, durante la dictadura, en la zona de Bariloche hubo formas de resistencia, o más bien estrategias individuales para sobrevivir a este período?

LP: Más lo segundo, formas de resistencia yo no vi. Sí, estrategias individuales para sobrevivir. Creo que hubo también problemas antes de la dictadura en el hospital. En el hospital había muchos médicos de Buenos Aires, buenos médicos, jóvenes, que se radicaron en Bariloche a principios de los setenta y querían hacer un cambio para que el hospital funcionara bien, como tiene que funcionar un hospital, entonces mucha gente dejó de atenderse en las clínicas privadas y se atendía en el hospital que era mucho mejor. Bueno, entonces los médicos fueron considerados comunistas porque atendían bien a la gente humilde. A uno de estos médicos le pusieron una bomba... También me acuerdo de haber pasado la frontera a Chile en el setenta y ocho, que creo que fue la primera vez que cruzamos, y en la aduana argentina había dos o tres afiches grandes, de personas buscadas por la policía como en los westerns, y había un afiche con la foto del poeta Juan Gelman por ejemplo, y no recuerdo de quién más... Tampoco había el movimiento de reivindicación de las comunidades mapuche que hay ahora, de eso no se podía ni hablar.

$\mathrm{CH}$ : Con respecto a Chile... Vos contaste la primera vez que nos encontramos que en algún momento empezaron a encontrarse un grupo de intelectuales, artistas, autores de Bariloche con autores chilenos, pero quizá fue posterior.

LP: Yo no tuve mucho contacto con escritores chilenos. Salvo con Marcela Cruzat, escritora de Concepción, Chile, que vino en el ochenta y cuatro a Bariloche. En los noventa dictamos talleres literarios. Ella difundía autores chilenos, y yo autores argentinos. Marcela escribía, no sé si sigue escribiendo. Tiene un libro editado que se llama Crónicas de Ismael, que fue Premio Municipal Bariloche y es un muy buen libro. Al que conocí también después de la dictadura, fue a Gonzalo Rojas, un gran poeta chileno, de Lebu, a quien le hice una entrevista y nos mantuvimos en contacto.

Lebu (del mapudungún leuvu = río) es una ciudad y comuna chilena, capital de la provincia de Arauco, inserta en la Región del Biobío, se localiza a $145 \mathrm{~km}$ al sur de la ciudad de Concepción, capital regional.

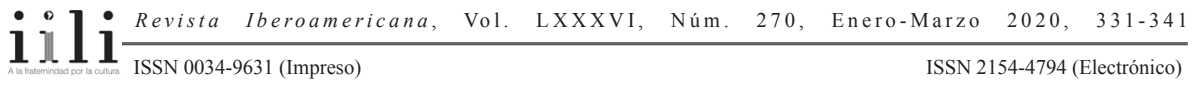


Durante la dictadura de Pinochet, él fue desterrado por haber sido consejero cultural de Allende en China y encargado de negocios en Cuba. Durante la dictadura chilena vivió en la República Democrática Alemana.

$\mathrm{CH}$ : En tu caso entonces no hubo mucho contacto con los chilenos. ¿Vos dirías que fue solo así en tu caso, o que fue un fenómeno general, no tener mucho contacto con el lado chileno?

LP: A mí me parece que esto se inicia a fines de los noventa, cuando en Chile se termina la dictadura.

CH: ¿Vos dirías que los escritores de Bariloche tenían una noción de grupo, de ser escritores patagónicos, o de haberse venido a la Patagonia, y que se distinguían, por ejemplo, de los escritores porteños o de otras zonas?

LP: Pensá que la democracia se empieza a vivir desde el ochenta y tres, y recién a fines de los ochenta y a principios de los noventa se empieza a crear, a mí modo de ver (por ahí puedo estar equivocada), una conciencia de que no hay que estar tan pendiente del centralismo que implica Buenos Aires. Eso también les pasa a los pintores, a los artistas plásticos, que incluso están más desconectados, porque vos para hacer obra tenés que ver obra, ver qué está pasando. Para los escritores es más fácil tener acceso a lo que se escribe... De todos modos, para volver a tu pregunta: Sí, se estaba empezando a tener una noción de grupo, incluso se intentó formar una asociación de escritores, pero eso siempre fracasó por la parte burocrática... Pero hubo una época, inmediatamente después de la dictadura, en que ya nos reuníamos en la Biblioteca Sarmiento de Bariloche. Éramos un grupo: Graciela Cros, Manuel Bendersky, Marcela Cruzat, María Ester Marteleur, Cecilia Fresco, Laura Calvo, Esteban Buch, Elena Bianchi y ahí nos reuníamos y hacíamos algo como un taller. Venían también los poetas Norberto Covarrubias y Norberto Uman desde Buenos Aires, como para darnos algunas bases de taller de escritura creativa. Yo aprendí mucho de ellos, y además había hecho taller en Buenos Aires, antes de radicarme en Bariloche. Bueno, ellos nos impulsaron y venían periódicamente, y así se empezó a armar el grupo. Pienso que necesitábamos comunicarnos, compartir después de tanto silencio, y esa fue la época en que yo estaba gestando mi novela Todo eso oyes. Nuestro grupo duró como dos o tres años, después se fue disolviendo. Ahora vos me preguntás si había una conciencia de escritores patagónicos. En ese momento todavía no sé, en ese momento lo que pasaba era que muchos no tenían una residencia de tanto tiempo en Patagonia, si querés por ahí Graciela y yo sí, pero el resto eran más recién llegados y de distintos lugares del país, no solamente de Buenos Aires. Entonces me parece que era como que recién se empezaba a gestar una conciencia. Yo creo que la conciencia de que escribimos desde la Patagonia, viviendo en la Patagonia, es más a partir de los noventa. De todas maneras, yo la estaba empezando a tener a mediados de los ochenta, cuando empecé a escribir Todo eso oyes, mi primera novela. También surge, en esa

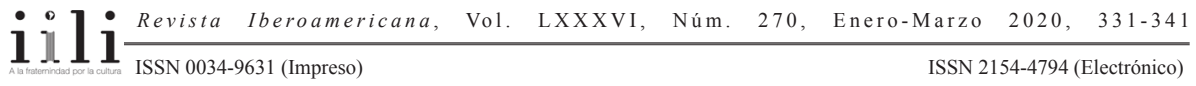


primera novela mía, el tema de la identidad mapuche que estaba taponada, entonces todo eso hace que yo empiece a tomar conciencia de qué estoy haciendo acá, dónde estoy parada, de qué estoy escribiendo, y sobre qué, y de alguna manera en toda la escritura actual de la Patagonia, la que está apareciendo ahora y ya hace unos años, se produce un cambio muy grande, porque ¿qué había sobre Patagonia cuando por ejemplo yo llegué? Estaban los cronistas extranjeros que, con su curiosidad hacia lo desconocido, miraron y describieron sus viajes como una aventura. O los argentinos, como el Perito Moreno y Clemente Onelli, que aportan una cantidad de datos, pero es un tipo de literatura que tuvo su etapa. Después vienen los otros cronistas, los locales, que no se consideran a sí mismos escritores, me refiero a los pobladores de principios del siglo XX, que quieren contar su experiencia, es el caso de Asencio Abeijón, el de las Memorias de un carrero patagónico -hay muchos casos como el de Abeijón, que en un momento de su vida tienen la necesidad de poner por escrito lo que vivieron, la experiencia patagónica, como también Elías Chucair, que escribe sobre la bandolera inglesa. Y después llegamos otros que venimos de distintos lugares de la Argentina, tenemos otra experiencia, y una identidad literaria más definida. No solamente la cronista o testimonial. Igual hoy día la crónica está muy en boga, hay muchos escritores que recurren a la crónica, o que escriben crónicas actuales, ya no de la vivencia de aquella época. Este es el caso por ejemplo de María Sonia Cristoff, ella es de Trelew y conoce muy bien la zona, y uno de sus libros, Falsa calma, es una crónica excelente. O aquí tenés un escritor como Emilio Di Tata Roitberg, que lo que narra está centrado en Bariloche, pero sobre todo en el Bariloche actual, y todo lo que eso implica, el cambio regional, mundial, la droga, la delincuencia, el turismo, en lo que se ha convertido Bariloche, que no tiene nada que ver con los cronistas de principios del siglo XX, esa es otra historia, y lo interesante es que ha ido evolucionando.

CH: Tengo la sensación de que en los años ochenta, noventa, cuando se está empezando a formar una conciencia literaria en la Patagonia, estos autores, incluyéndote a vos, provienen también de la lectura de la nueva novela latinoamericana de los sesenta y de sus mecanismos literarios muy especiales, que emplean también en sus textos.

LP: Totalmente de acuerdo. Yo en la Patagonia vi cosas que me recordaban el realismo mágico sin necesidad de inventar nada. Pero al mismo tiempo, al ser esta una región tan distinta de la zona donde nace el realismo mágico, que es la exuberancia tropical, había que narrarlo de una manera más austera, porque la austeridad de la región influye, y además tampoco interesaba caer en lo que ya se había hecho.

CH: Especialmente en Todo eso oyes, desde el título está presente Rulfo, parece el gran autor de referencia de este libro...

LP: Sí, te diría que sí, sin embargo, fijate que dentro de la corriente del realismo mágico Rulfo es el menos característico, es el más austero. Y a mí otro autor que no está dentro del realismo mágico y que me interesa mucho es Manuel Puig, me encanta

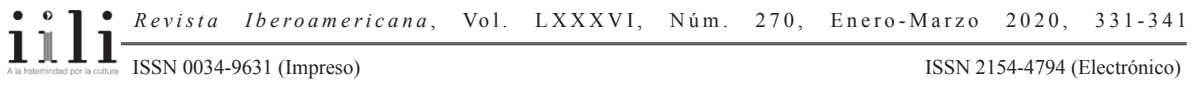


cómo abre el juego de la novela y mete todo lo que se considera subgénero. Eso me interesa mucho, son las influencias, los padres literarios que se tienen.

$\mathrm{CH}$ : Lo que también veo en estos padres literarios es el experimento, la metarreflexión, que igualmente está muy presente en tus textos: la metarreflexión sobre el intento de escribir una novela y lo que implica, por ejemplo en La doble vida. Diría que es una constante también en lo que llamaría la 'nueva novela patagónica'. Está presente p. ej. en la única novela de Graciela Cros, Muere más tarde; en la novela de la autora fueguina Anahí Lazzaroni, En esta ciudad se escribirá una novela; o en Trelew, de Marcelo Eckhardt. En estas novelas la metarreflexión siempre se relaciona de algún modo al lugar desde donde se escribe, la Patagonia, y casi diría que convierte el acto de escribir en un acto fundacional.

LP: Sí, claro, el género novela permite eso. Pero salvo la de Anahí Lazzaroni, las otras novelas que mencionás fueron escritas unos cuántos años más tarde que Todo eso oyes y La doble vida. También lo que yo comprobé al llegar aquí fue que, salvo Graciela Cros, no tenía interlocutores. Y creo que esa fue una de las razones por las que empecé a dictar talleres de escritura creativa y de lectura, para compartir lo que me apasionaba. Por ahí yo necesitaba, en un momento muy difícil de mi país, hacer esas metarreflexiones, preguntarme para qué escribía, a dónde iba, qué quería; era una necesidad, casi como llevar un diario. Y entonces, a través de esos talleres, va apareciendo gente muy interesante, gente que se va formando, como Carolina Biscayart, Adrián Moyano, Horacio Herman, Emilio Di Tata Roitberg, Albertina Rahm, Laura Calvo, incluso Pablo Bernasconi (extraordinario ilustrador) y muchos otros.

$\mathrm{CH}$ : La metarreflexividad en general es un rasgo muy presente en la literatura argentina posdictatorial, pero la veo todavía más exacerbada en la novela patagónica, donde esa reflexión está relacionada con una tradición escasa. Hay mucho relato de viaje sobre la Patagonia, hay textos escritos desde afuera de la Patagonia sobre la zona, pero hasta la segunda mitad del siglo XX hay relativamente poca ficción narrativa o novela sobre la Patagonia. La metarreflexividad en la novela patagónica acompaña entonces su misma fundación, que a su vez exige una reflexión sobre qué se hace al describir o escribir la Patagonia.

LP: Sí claro, por lo menos yo con mis novelas, quise hacer algo distinto. No escribir la mera crónica de una experiencia, de cómo cazaste un puma, qué sé yo, que puede ser muy interesante, o cómo esquilás una oveja, o cómo cazás un chulengo; yo no quería hacer eso, sino intentar de ver esta región con ojos nuevos, como si fuera una marciana, ver qué es esto, qué es lo que pasa aquí, y eso me fue llevando a toda una revisión de cosas de mi país.

$\mathrm{CH}$ : Me acuerdo que justo habíamos estado hablando en otra ocasión de eso con respecto a la novela de Ricardo Costa, Fauna terca, que, junto a tu Todo eso oyes, es la primera novela patagónica que trata de la presencia de la dictadura en la Patagonia... En

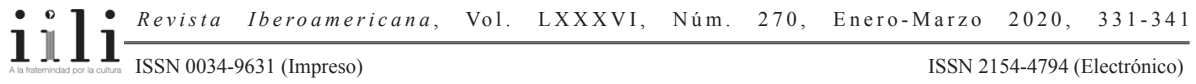


las dos novelas es como si hubiera un mundo de los muertos, víctimas de la dictadura, desde el que se está hablando. Justamente como ya lo dice tu título, Todo eso oyes: esos murmullos, como en Pedro Páramo, son voces de muertos que resucitan en las cartas...

LP: Sí, pero además creo que Todo eso oyes no plantea la famosa dicotomía de Sarmiento de civilización urbana y barbarie rural, sino la barbarie a secas. La que supuestamente comienza en mi país con los 'indios' y culmina en la barbarie de la última dictadura militar. En 1989, cuando se publicó Todo eso oyes, salvo Respiración artificial de Ricardo Piglia, no se habían publicado en Argentina novelas sobre la dictadura. Si me preguntás por qué, te diría que lo que pasa es que había muchos autores que estaban exiliados, que no estaban viviendo acá y recién cuando volvieron pudieron procesar todo lo que había pasado y escribirlo. De todas formas, yo me acuerdo que me iba con los originales de esta novela a mi trabajo -en esa época trabajaba en una inmobiliaria. Me acuerdo que llevaba los manuscritos escritos a máquina (no había computadora entonces) dentro de una carpeta para no separarme de mi material. Te estoy hablando del año ochenta y cuatro o ochenta y cinco, la novela se publicó en el ochenta y nueve. Y todavía en los noventa, cuando mi hijo mayor tuvo que hacer el servicio militar, que entonces era obligatorio, tuve miedo por algunas cosas que escribo en la novela, pensando paranoicamente que los militares la iban a leer y le iban a hacer la vida imposible. Pero jamás iba a suceder eso porque los militares no leen.

$\mathrm{CH}$ : A pesar de este miedo, la presencia de la dictadura está muy marcada en Todo eso oyes.

LP: Fue algo muy fuerte, me marcó también en La doble vida, y en Nadie baila el tango, no pude evitarlo. Yo creo que nos marcó a todos, a pesar de que mucha gente después quiso olvidar... Yo a veces pienso que toda mi narrativa gira alrededor del tema de la memoria. Pero también -como vos comentás- reflexiona sobre el proceso de escritura y sobre la frontera entre realidad y ficción. La trama de La doble vida, que alterna el diario personal de una escritora con el borrador de su novela, me permitió incorporar al texto la realidad de la protagonista y sus comentarios sobre lo que está escribiendo, y también incluir pantomimas, poemas, canciones y citas de autores que le/me interesan. Como ya lo había hecho en las posdatas de la correspondencia de Todo eso oyes, incluí "notas al margen" que revelan las dificultades con que la autora se enfrenta al escribir su novela y cómo las va resolviendo.

$\mathrm{CH}$ : ¿Y qué lugar tiene en esto la Patagonia? En Todo eso oyes el proceso de la memoria ocurre desde Buenos Aires, desde donde el protagonista reconstruye su historia vivida en la Patagonia.

LP: Situé a la protagonista de La doble vida en la Patagonia. Es un alter ego mío: una porteña que durante la dictadura se refugia en el sur. Y también recuerda. Fabula y recuerda. Después está el hecho de que, al escribir, siempre intento ver a los personajes y los lugares como una extranjera. A veces es sólo a través de esa mirada

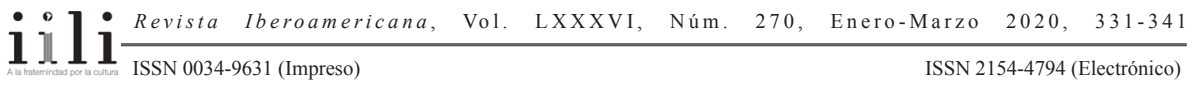


extranjera que una puede ver, que una puede verse. Es la mirada de los poetas, el don de recuperar lo nuevo, lo inaugural de las cosas cotidianas. Justamente mediante esa 'extrañeza' podemos separar las cosas del hábito de lo cotidiano. Así intenté ver esta Patagonia que comenzaba a descubrir.

$\mathrm{CH}$ : ¿Podría decirse entonces que la mirada y la memoria son los temas y mecanismos centrales de tu narrativa?

LP: Creo que sí. Me importan la mirada, el tono o registro, y sobre todo escribo contra el olvido. Tal como dice Ciriaco Larra en Todo eso oyes: "Escribir es una forma de no morir. Por eso comencé estas notas; contra esa muerte que se llama olvido."

$\mathrm{CH}$ : También en Nadie baila el tango la memoria es central.

LP: Totalmente. Y también mi pertenencia a Buenos Aires, donde nací y residí hasta 1977.

CH: Sí, es verdad, esta novela está completamente ubicada en Buenos Aires. ¿Por qué este cambio de lugar para situar la acción de tu texto?

LP: Lo que pasa es que yo la empecé a escribir partiendo de unos cuentos, donde contaba cosas muy autobiográficas de mi infancia, y eso pasaba todo en Buenos Aires. Eso fue lo que me determinó. El contar episodios de cuando yo era chica, de la enfermedad de mi madre, de contar cómo era el barrio, todo eso determinó que transcurriera en Buenos Aires (aunque también incluye un viajecito a Bariloche). Toda esa primera parte es autobiográfica, después ya no. Es una novela, a través de la cual quiero contar una verdad, pero no es un testimonio. Ni pretende. Pero la elección del lugar fue por eso, porque yo empecé contando las cosas que me pasaron a mí. Muchas veces empiezo a escribir cuentos así... y estos a veces desembocan en novelas. Fijate que Todo eso oyes empezó como narraciones sueltas y yo no la podía editar porque no tenía dinero y nadie me conocía, porque solamente había editado un libro de poesía o dos y no te conocen por eso, y más viviendo en la Patagonia. Entonces me digo, bueno, para poder editar esto, tengo que mandarla a concurso, y no hay concursos de libros de cuentos, no había en esa época, había de novela. Entonces dije la transformo en una novela, y ahí se me ocurrió la idea de las cartas... Mirá, ya te estoy contando toda la 'cocina'. Así se me ocurrió la idea de las cartas: vamos a hacer que una persona le mande estas historias a otra para que la novela tenga un hilo conductor que la sostenga. En el caso de La doble vida, me pasó que me enteré de que en Editorial Atlántida estaban armando una colección de autores argentinos. Yo tenía unos cuentos, y fui y pregunté ¿esto les puede interesar? Ahh sí, pero nos interesa más una novela. ¿Se anima a transformarlos en una novela? ¡Un karma! Entonces digo bueno, total ya lo hice antes, voy a probar, e invento lo de la escritora que lleva un diario personal donde también intercala sus ficciones, y ahí va. De alguna forma traicioné mis cuentos. Pero la última, Nadie baila el tango, ya la pensé como novela.

$\mathrm{CH}$ : Así que, a pesar del cambio de escenario, Nadie baila el tango se enlaza muy bien con tus novelas 'patagónicas' anteriores. 
LP: En los protagonistas de las dos novelas anteriores, aparece la pertenencia a mis dos regiones entrañables: Buenos Aires y Bariloche, donde resido desde 1977. Pero Nadie baila el tango cuenta hechos de la historia de mi país a través de las vicisitudes en Buenos Aires, de una mujer de clase media acomodada, que va creciendo a través de estos cambios. En su historia, que narra en primera persona, van apareciendo los prejuicios y la hipocresía de la clase media, las dictaduras militares, el machismo encarnado en el tango y, sobre todo, lo que a la protagonista le sucede durante el proceso. Esta novela se emparenta entonces con mis dos novelas anteriores en que planteo el tema de la memoria, y en que creo que también escribo contra esa muerte que se llama olvido.

Siempre pienso que se escribe contra algo:

Contra qué escribí mis novelas:

Contra el olvido

Contra la dictadura militar

Contra los militares

Contra el terrorismo de estado

Contra todo terrorismo

Contra Leopoldo Lugones

Contra el nacionalismo

Contra la guerra de Malvinas

Contra el machismo

Contra los prejuicios y la hipocresía de la clase media

Contra la educación religiosa

Contra esta Argentina que es federal solo en los papeles

CH: Muchísimas gracias, Luisa. 
